\title{
Influence of anticancer drugs on DNA methylation in liver of female mice
}

\author{
Shaden Muawia Hanafy ${ }^{1}$, Tarek Abd El-Raouf Salem ${ }^{1}$, Amal Ahmed Abd El-Aziz ${ }^{1}$, \\ Bahgat Abd El-Ghafar El Fiky ${ }^{2}$, Mahmoud Abd El-Azeim Shokair ${ }^{1}$
}

\footnotetext{
${ }^{1}$ Molecular Biology Department, Genetic Engineering and Biotechnology Institute, Minufia University, Shibin El Kom, Egypt;

${ }^{2}$ Animal Biotechnology Department, Genetic Engineering and Biotechnology Institute, Minufia University, Shibin El Kom, Egypt. E-mail: shadenmuawia@yahoo.com
}

Received 18 March 2011; revised 16 May 2011; accepted 29 May 2011.

\begin{abstract}
Epigenetic changes such as DNA methylation regulate gene expression in normal development. Methotrexate and Adriamycine are antineoplastic drugs that target DNA and enzymes acting on DNA. We aimed to evaluate their cytotoxic effect on cell lines and on female mice to investigate the in vivo influence of both drugs on the DNA methylation and subsequently the protein expression. The total level of DNA methylation showed a significant reduction from $62.2 \%$ to $36.7 \%, 36.6 \%$ as compared to control group, when using different doses of MTX and ADR. Hepatic protein pattern revealed five bands with low MW (16 - 6.1 KDa) in acute and LD50 doses. In conclusion DNA methylation is influenced by anticancer drugs in a dose-dependent manner. Some specific protein fragments may be considered as a potential markers associated with high dose of anticancer drugs.
\end{abstract}

Keywords: Epigenetic; DNA Methylation; Methotrexate (MTX); Adriamycine (ADR)

\section{INTRODUCTION}

Cancer is uncontrolled growth of cells coupled with malignant behavior; invasion and metastasis. It is thought to be caused by the interaction between genetic susceptibility and environmental toxins. Most of chemotherapeutic drugs work by impairing mitosis and/or inducing apoptosis. Several anticancer drugs target DNA or enzyme acting on the DNA [1]. The resistance of tumor cells to different antineoplastic agent is an obstacle for cancer chemotherapy. The main mechanism in drug resistance is the multi-drug resistance (MDR) phenomenon, which constitutes the reduction of intracellular drug level due to the P-glycoprotein pump function [2]. Drug development programs for identification of new cancer chemotherapeutic agents involve extensive preclinical evaluation of vast numbers of chemicals for detection of antineoplastic activity. Animal models have always played an important role, and also cell culture systems have figured largely in the field of cancer chemotherapy, where the potential value of such systems for cytotoxicity and viability testing is now widely accepted [3].

Methotrexate (MTX) - is an antimetabolite and antifolate drug which is used in treatment for many neoplastic disorders and some autoimmune diseases. It inhibits the synthesis of nucleic acids and subsequently proteins [4]. However, MTX, at certain dose, exhibited a toxic side effect to normal cells and organs in the body. Also, using of MTX for long period can increase the risk of toxicity [5]. Many studies proved the ability of MTX to inhibit dihydrofolate reductase enzyme (DHFR) which converts dihydrofolate to the active tetrahydrofolate compound which is essential for DNA methylation. [6]. Adryamycin (ADR) is an anthracycline isolated from streptomycin peucetius. It is commonly used in the treatment of a wide range of cancer including haematological malignancies, carcinomas, sarcomas and lymphomas. It prevents DNA replication by acting as topoisomerase inhibitor [7].

DNA methylation is a major biochemical modification, typically occurs at 5'-CpG (Cytosine-phosphate-guanine sites). They are regions have a higher GC content than the genome average and they may repress transcription [8]. In mammals, almost $60 \%$ of all promoters localize within $\mathrm{CpG}$ region. These regions are commonly devoid of methylation, while the rest have a methylation pattern and base composition indistinguishable from bulk DNA [9]. There is an inverse relationship between $\mathrm{CpG}$ methylation and transcriptional activity. Evidence that has 
accumulated in the past 10 years suggests that cancer cells usurp this physiologic mechanism and use it to their benefit by inactivating tumor suppressor genes leading to cancer progression. Hypomethylating agents or DNA methylation inhibitors could be used for the reversal of aberrant DNA methylation and therefore restore the function of silenced genes in cancer causing growth arrest in tumor cells $[10,11]$. Upon these observations, we designed this work to investigate the potential activity of two common anticancer drugs, MTX and ADR as DNA hypomethylating agents that may lead to hyper expression of some genes associated with tumor suppression.

\section{MATERIALS AND METHODES}

\subsection{Cell Lines and Cytotoxic Drugs}

Three different types of cell lines were used for in vitro study; human larynex carcinoma cell line (Hep2, ATCC No. CCL-23), human hepatocyte carcinoma cell line (HepG2, ATCC No. HB-8065) and monkey kidney cell line (Vero, ECACC No. 84113001). Cell lines were maintained and grown in RPMI culture medium supplemented with $15 \%$ fetal bovine serum (FBS), $10 \mathrm{mmol} / \mathrm{L}$ HEPES, $1 \mathrm{mmol} / \mathrm{L}$ sodium pyruvate, $4.5 \mathrm{~g} / \mathrm{L}$ glucose, 1.5 $\mathrm{g} / \mathrm{L}$ sodium bicarbonate, and $5 \%$ penicillin/streptomycin (Reagents and chemicals were obtained from Sigma/Aldrich, USA). Two different chemotherapeutic drugs were used, methotrexate $(10 \mathrm{mg} / 1 \mathrm{ml}$; Ebewe Co. Italy) and adriamycin $(2 \mathrm{mg} / 1 \mathrm{ml}$; Pharmacia Co. Italy). Drugs were diluted in $0.9 \%$ physiological saline for $1 \mathrm{X}$ concentration.

\subsection{In-Vitro Cytotoxic Study}

Cells were seeded in 96-well flat-bottomed microtiter plates $(100 \mu \mathrm{l} /$ well $)$ under complete aseptic condition and incubated in $5 \% \mathrm{CO}_{2}$ incubator at $37^{\circ} \mathrm{C}$ for $24 \mathrm{hr}$ to reach complete monolayer. Serial dilutions of tested drugs were titrated in triplicate to the cells; in addition to the control wells that left without drugs. The plate was then incubated in $5 \% \mathrm{CO}_{2}$ incubator at $37^{\circ} \mathrm{C}$ for $24 \mathrm{hr}$ and $72 \mathrm{hr}$ to investigate the LD50 and cytopathic effect of the tested drugs. For recovery period bioassay, plates were incubated for 7 days in which growth medium was renewed every 2 days.

\subsection{In-Vivo Cytotoxic Study}

The toxicity study was carried out using 70 female Balb/c mice weighing $20-25 \mathrm{~g}$ each. They were maintained on animal cubes (Feeds Nigeria Ltd), provided with water ad libitum and were allowed to acclimatize to the laboratory conditions for seven days before the experiment. Three doses were selected for each drug according to LD50 determinaion on cell lines: For adria- mycine; $0.4,0.04$ and $0.004 \mathrm{mg} / 100 \mathrm{~g}, \mathrm{BW}$ for acute, LD50 and therapeutic dose, respectively. While, For metotrexate; 2, 0.2 and $0.02 \mathrm{mg} / 100 \mathrm{~g}$, BW for acute, LD50 and therapeutic dose, respectively. Animals were divided randomly into 7 groups (10 mice each), six groups of animals were injected subcutaneously with these dosese three times a week for 1 month. In addition, ten normal non-injected mice served as control.

\subsection{Biochemical and Hematological Investingtions}

The serum activity of liver enzymes, ALT and AST, were determined according to the method of Reitman and Frankel [12]. Also, serum albumin [13], urea [14] and creatinine [15] were estimated. On the other hand, level of haemoglobin $(\mathrm{Hb})$ and total leucocytic count [16] were determined.

\subsection{Histopathological Examination}

At the end of experiment, animals were sacrificed by cervical dislocation. Liver, kidney and spleen were immediately excised and processed for histopathological examination. Briefly, paraffin sections of fixed tissues were cut in $5 \mu \mathrm{m}$ thickness; stained with hematoxylin and eosin (H\&E) and then examined microscopically. Histopathological changes were graded according to Portmann, et al. [17].

\subsection{SDS-PAGE for Hepatic Proteins}

Half gram of liver tissue was placed in ice-cold PBS, minced and homogenized by using Teflon-glass homogenizer. The homogenates were spun and the clear supernatants were transferred into clean tube, the protein content was determined according to the method of Bradford [18]. Analysis of hepatic proteins was carried out by using SDS-polyacrylamide gel electrophoresis (SDS-PAGE) as described by Laemmli [19]. Briefly, total protein liver extracts $(20 \mu \mathrm{g})$ from different groups of animals were loaded onto $15 \%$ polyacrylamide gel and subjected to $80 \mathrm{~V}$ for 30 minutes. At the end of migration, gel was stained with Coomassie blue for $2 \mathrm{hr}$ and then the excess of stain was removed by using glacial acetic acid for $4 \mathrm{hr}$. The gel was visualized by using white light and photographed.

\subsection{Determination of Hepatic DNA Methylation Analysis}

Isolation of the mouse hepatic DNA was done by using DNeasy Tissue Kit (Qiagen, Germany). For restriction analysis, we used two enzymes-Msp I and Hpa II (Moraxella species and Haemophilus parainfluenzae, respectively, MBI, Fermentas, Lithuania). Both enzymes cut DNA in the sequence: 


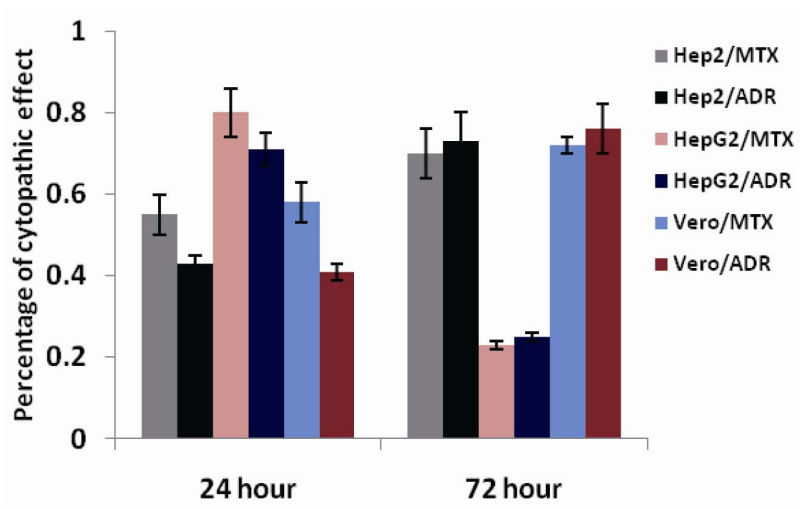

Figure 1. Percentage of cytopathic effects $24 \mathrm{hr}$ after incubation with drugs and recovery percentage after $72 \mathrm{hr}$ from drugs elimination.

$$
\begin{aligned}
& \ldots . .5 \text { '....C } \downarrow \text { CGG.....3', } \\
& \text {.....3' } \ldots . . . \mathrm{GG} \mathrm{C} \uparrow \mathrm{C} \ldots . .5
\end{aligned}
$$

MspI and HpaII differ in sensitivity to DNA methylation. MSPI cleaves outer and inner methylated cytosines (mCCGG or CmCGG). While Hpa II cleaves outer cytosines in this DNA sequence (mCCGG). On this base, we could to determine the percentage of methylated fragements of genomic DNA. The samples of DNA were analyzed by using $1 \%$ agarose gel in TAE buffer containing ethidium bromide (at final concentration of 1 $\mathrm{mg} / \mathrm{ml}$ ) [20]. 1kb DNA (ladder 250 - 10000 bp-Promega, USA) was used as standard DNA. The electrophoresis was performed at $100 \mathrm{~mA}$ for 3 hours. Individual fragments of DNA were detected by UV-trans-illuminator and photographed. For densitometrical scanning of DNA preparations and data evaluation, we used the Gel documentation system, the software Microsoft Photo Editor, Ingenius Syncene Bioimaging, Canada, software version 5 .

\subsection{Statistical Analysis}

Statistical analysis was done using the statistical package SPSS version 10. Comparison of mean values of studied variables among different groups was done using ANOVA test. $p<0.05$ was considered to be significant.

\section{RESULTS}

\subsection{In-Vitro Cytotoxicity Study on Hep2, HepG2 and Vero Cell Lines}

He percentage of cytopathic effect of MTX and ADR were calculated and presented in Figure 1. Results showed that MTX exhibited higher cytopathic effect against HepG2, Hep2 and Vero cell lines as compared to that of ADR after $24 \mathrm{hr}$ exposure. Furthermore, HepG2 cells were more susceptible to the toxicity of MTX and ADR as it exhibited a significant percentage of growth

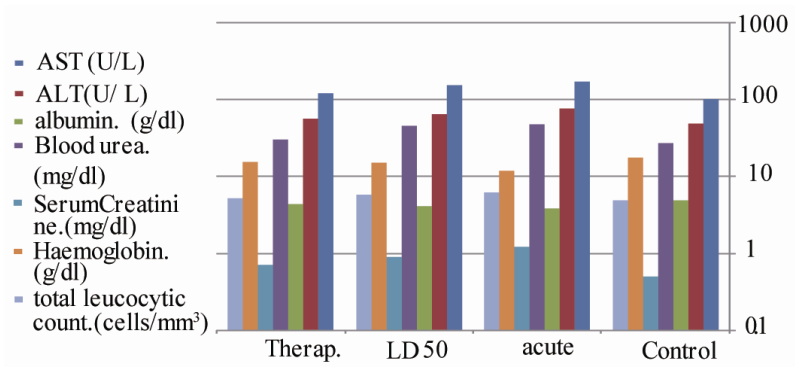

Figure 2. Biochemical parameters among different injected groups with ADR compared to control.

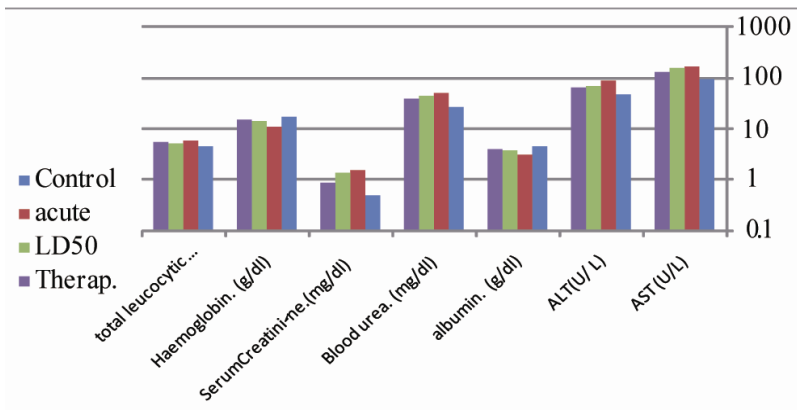

Figure 3. Biochemical parameters among different injected groups with MTX compared to control.
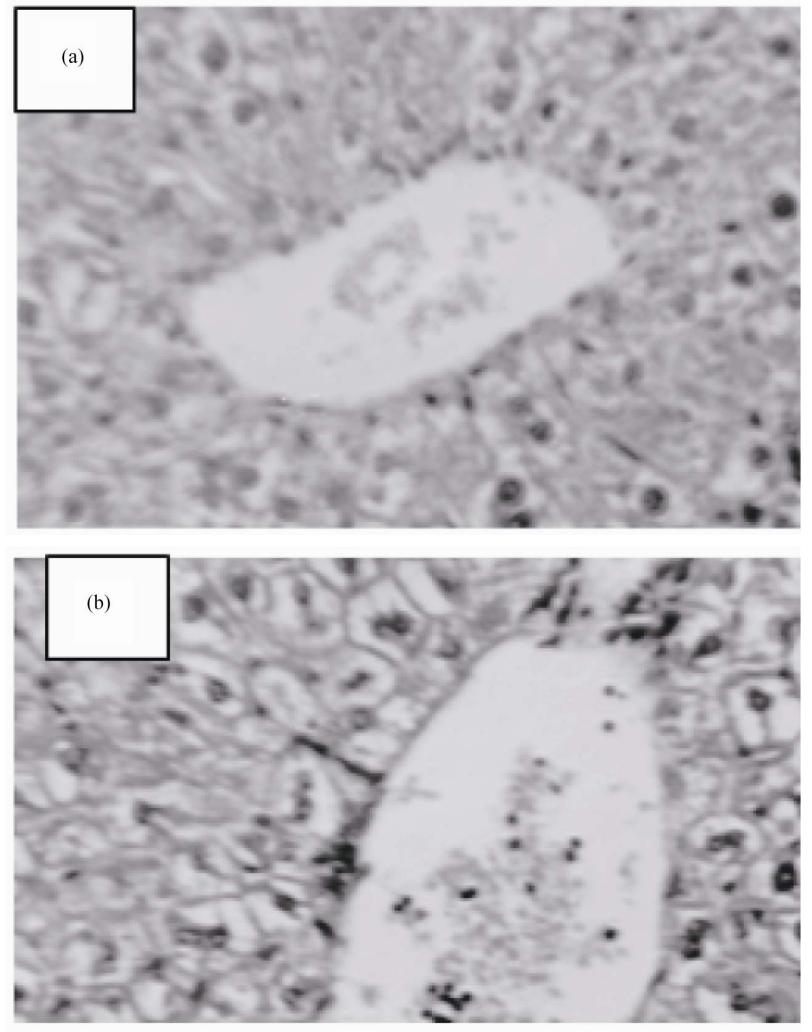

Figure 4. A photomicrograph of normal liver of female mice (a) and injected with therapeutic MTX (b) showing dilated central vein congested with blood cells, fatty changes and vacuolar degeneration of hepatocytes. 

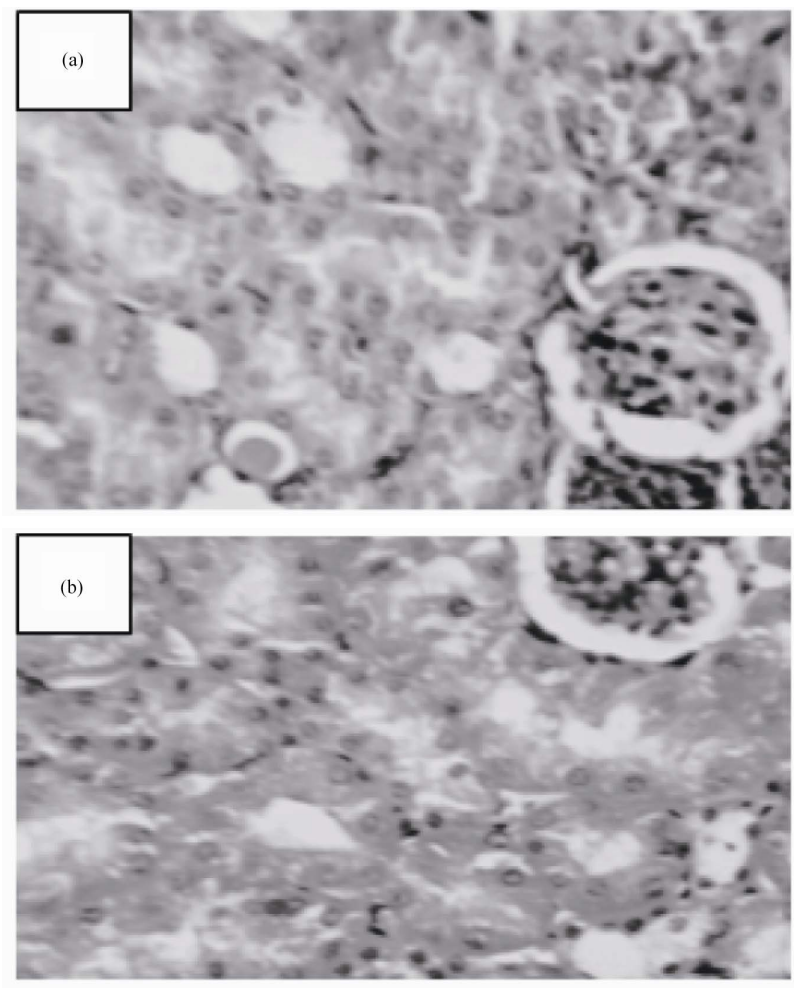

Figure 5. A photomicrograph of normal kidney of female mice (a) and treated with therapeutic ADR (b) showing normal pattern of glomeruli with normal subcapsular space, dilated cortical tubules and peritubular inflammatory cells.

inhibition $(79.1 \%$ and $71.5 \%$, respectively); while the percentage of recovered cells after $72 \mathrm{hr}$ were $23.6 \%$ and $25.7 \%$, respectively. In contrast, the Hep2 and Vero cell lines exposure time $24 \mathrm{hr}$ were more resistant to the cytotoxic effect of both MTX and ADR (54.6\% and $43.1 \%$ for Hep2, $58.2 \%$ and $41.6 \%$ for Vero cell line); while the recovery cells after $72 \mathrm{hr}$ proved the differential cytotoxicity for MTX and ADR.

\subsection{Biochemical and Hematological Investiga- tions}

Treatment of ADR group of mice with different doses, revealed a significant difference between the sub groups when compared with control. The difference was very highly significant in case of AST, blood urea, serum creatinine and haemoglobin. $(p=0.001)$ as shown in Figure 2. While, in case of MTX group. The difference was very highly significant between the subgroups compared to control in AST, ALT, blood urea and haemoglobin $(p=0.000)$ as shown in Figure 3.

\subsection{Histopathology}

Liver, kidney and spleen biopsies of female mice injected with therapeutic doses of MTX and ADR for one month showed some histopathological changes when
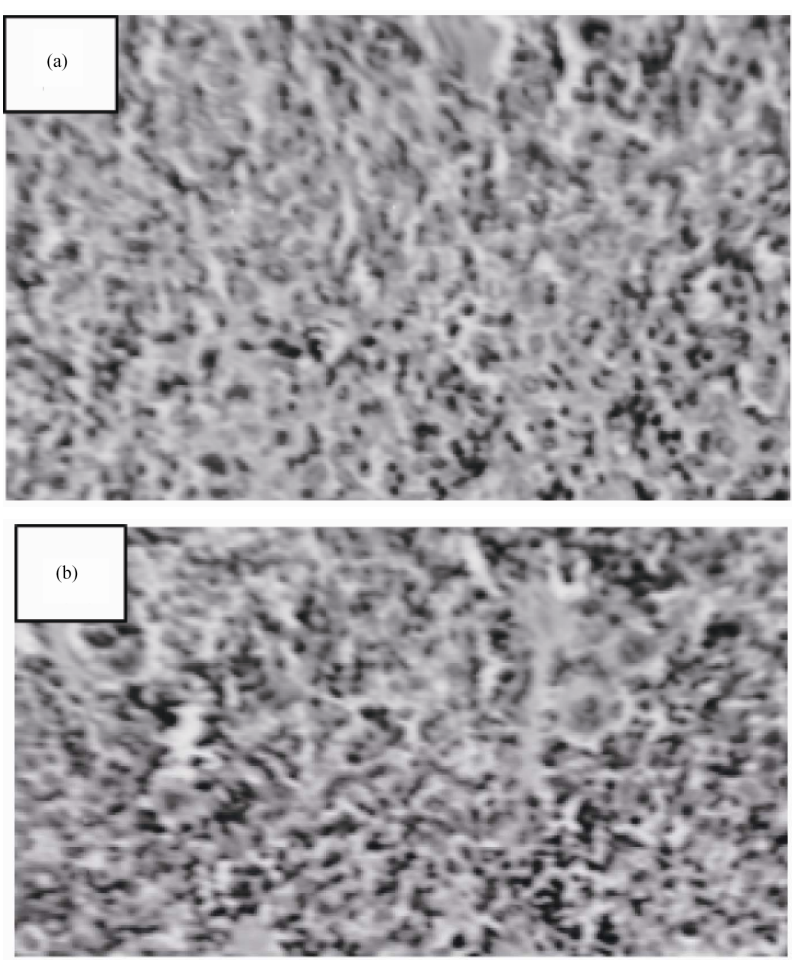

Figure 6. A photomicrograph of normal spleen of female mice (a) and treated with therapeutic MTX showing apoptosis and bleeding of splenic cells.

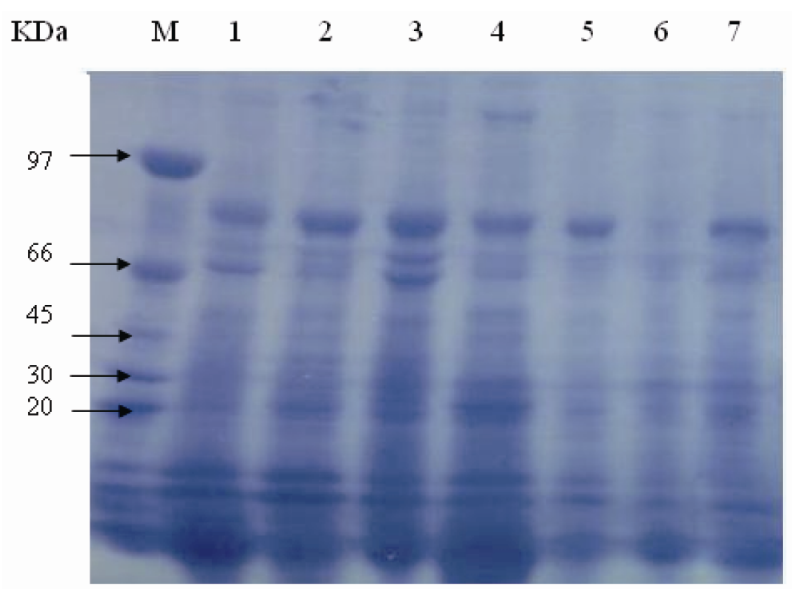

Figure 7. SDS-PAGE of hepatic proteins of studied groups: M: marker, Lane1: control, Lane2: Acute ADR, Lane3: LD50 ADR, Lane4: Therapeutic ADR, Lane5: Acute MTX, Lane 6: LD50 MTX, Lane7: Therapeutic MTX.

compared to normal control group as shown in Figures 4, 5, 6(a) and (b)). While, in case of toxic doses, it showed marked histopathological changes especially in kidney.

\subsection{Protein analysis}

Figure 7 illustrates the pattern of hepatic protein elec- 


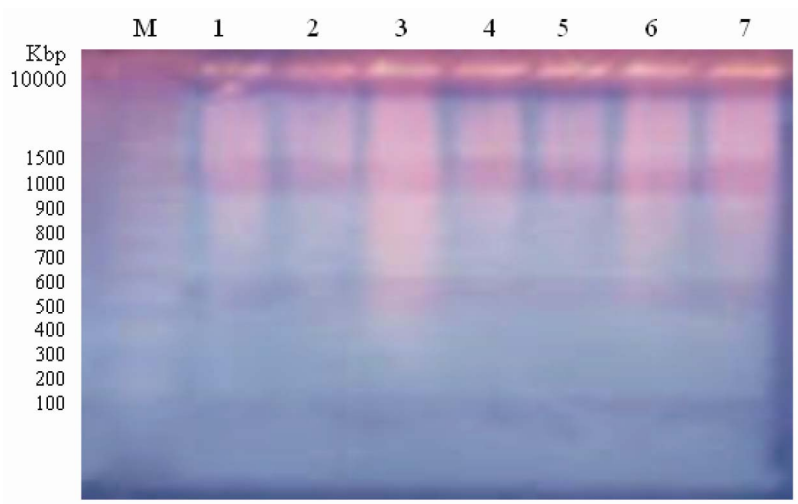

Figure 8. Msp I digestion of hepatic DNA isolated from the groups of study.

trophoresis of the studied groups of animals. Regarding the band with MW $130 \mathrm{KDa}$ was presented in normal and therapeutic ADR dose. The band which had MW $136 \mathrm{KDa}$ was presented in normal only and disappeared in all groups. The bands which had MW 134.06, 130.44, 120.30, 100.31 and 97.45 KDa were presented in normal and therapeutic ADR and therapeutic MTX. These bands were not observed in animals injected with acute and LD50 doses of ADR or MTX. This band can be considered as a potential marker associated with therapeutic dose of anticancer drugs. They showed appearance of two bands (18.1 and 16.7 KDa) in animals treated with acute, LD50 and therapeutic doses of ADR and MTX, while not shown in control groups. Five bands had been shown with low molecular weight (range size $16-6.1$ $\mathrm{KDa}$ ) in animals exposed to acute and LD50 doses of ADR and MTX. These bands were not observed in the controls, and in animals injected with therapeutic dose of ADR and MTX. These bands can be considered as a potential marker associated with high dose of anticancer drugs.

\subsection{DNA Methylation Study}

Representative electrophoreograms of hepatocyte DNA of control and injected groups digested with Msp I or HpaII were demonstrated in Figures 8 and 9. The electrophoreograms were scanned densitometrically. The scans were divided into molecular weight intervals calculated from the migration of the standard DNA. On densitometrical scans, curves of non-digested DNA and DNA treated by the restriction enzymes had different shapes. The shape of curves was influenced also by the MTX and ADR (Figures 9, 11(a) and (b)). On the basis of densitometrical scans, molecular weight distribution of products of DNA cleavage with restriction enzymes Msp I and Hpa II was calculated. The results of analyses of DNA fragments obtained by treatment with the restriction enzymes Msp I and Hpa II, summarized in Table 1.

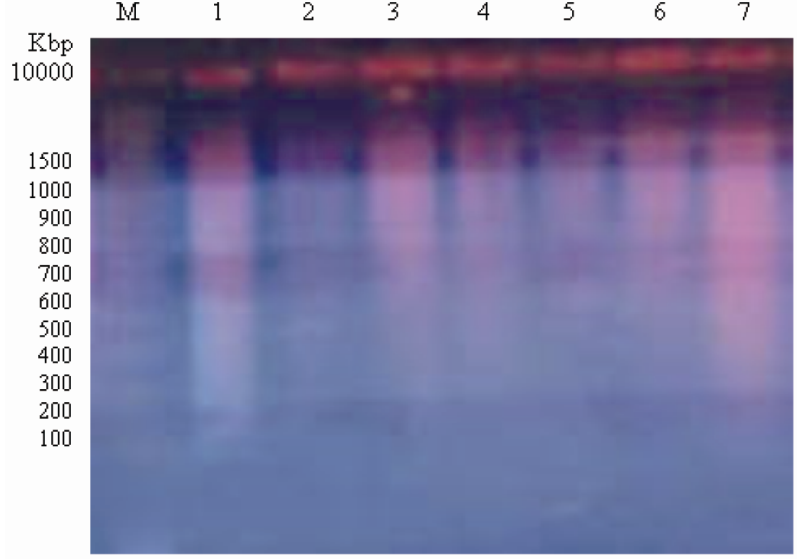

Figure 9. HpaII digestion of hepatic DNA isolated from the groups of study.
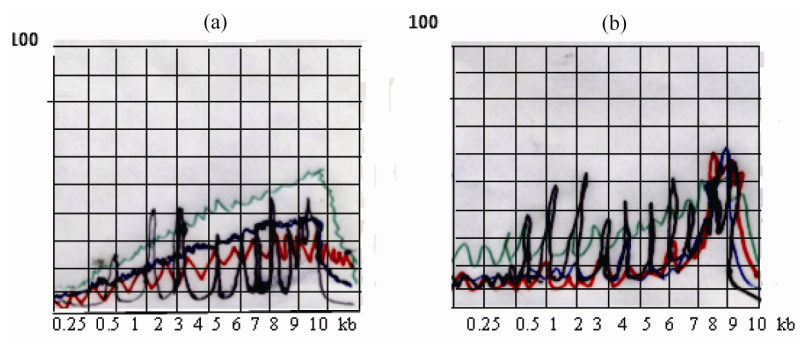

Figure 10. Densitometer scans of Msp I digested-hepatic DNA: (a) control and MTX groups (b) control and ADR groups. Where: Black line represents control dose, Green line represents LD50 dose, Red line represents acute dose,Blue line represents therapeutic dose.
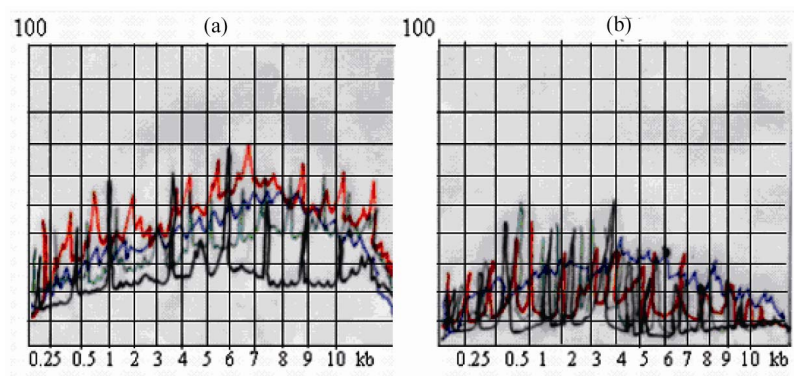

Figure 11. Densitometer scans of HpaII digested-hepatic DNA: (a) control and MTX groups (b) control and ADR groups. Where: Black line represents control dose, Green line represents LD50 dose, Red line represents acute dose,Blue line represents therapeutic dose.

It showed that the total level of DNA methylation was influenced not only by anticancer drugs but also by their doses. Treatments related alterations liver DNA methylation in the typical methylation sequence $\mathrm{C}-\mathrm{C}-\mathrm{G}-\mathrm{G}$ were expressed as a total methylation percentage in different MTX and ADR subgroups. Total methylation percentage was markedly reduced from $62.2 \%$ (control) to $36.7 \%$ by the action of the hypomethylating agents MTX and ADR. 
Table 1. Percentage of hepatic DNA methylation among different groups of the study.

\begin{tabular}{|c|c|c|c|c|c|c|}
\hline Sample & $\mathbf{N}$ & $\begin{array}{l}\text { MW } \\
\text { (Kb) }\end{array}$ & $\begin{array}{l}\text { Mn } \\
\text { (Kb) }\end{array}$ & $\mathbf{R}$ & $\begin{array}{c}\% \\
\text { Methylation }\end{array}$ & $\mathbf{P}$ \\
\hline \multicolumn{7}{|c|}{ Control } \\
\hline Msp I & 12 & 2.5 & 0.86 & 2.90 & 62.2 & 0.001124 \\
\hline Нpa II & 12 & 3.0 & 0.53 & 5.66 & & \\
\hline \multicolumn{7}{|c|}{ Therapeutic MTX } \\
\hline Msp I & 12 & 3.1 & 0.67 & 4.62 & 36.7 & 0.079478 \\
\hline Hpa II & 12 & 2.9 & 0.49 & 5.91 & & \\
\hline \multicolumn{7}{|c|}{ Acute MTX } \\
\hline Msp I & 12 & 1.75 & 0.69 & 2.53 & 38.0 & 0.001124 \\
\hline Hpa II & 12 & 3.21 & 0.50 & 6.42 & & \\
\hline \multicolumn{7}{|c|}{ LD50 MTX } \\
\hline Msp I & 12 & 3.01 & 0.78 & 3.85 & 39.3 & 0.001124 \\
\hline Нpa II & 12 & 2.89 & 0.56 & 5.16 & & \\
\hline \multicolumn{7}{|c|}{ Therapeutic ADR } \\
\hline Msp I & 12 & 3.7 & 0.97 & 3.81 & 36.6 & 0.003341 \\
\hline Нра II & 12 & 3.25 & 0.71 & 4.57 & & \\
\hline \multicolumn{7}{|c|}{ Acute ADR } \\
\hline Msp I & 12 & 2.25 & 0.74 & 3.04 & 37.0 & 0.079478 \\
\hline Нpa II & 12 & 3.01 & 0.54 & 5.57 & & \\
\hline \multicolumn{7}{|c|}{ LD50 ADR } \\
\hline Msp I & 12 & 3.32 & 0.81 & 4.09 & 36.9 & 0.003341 \\
\hline Hpa II & 12 & 2.99 & 0.58 & 5.15 & & \\
\hline
\end{tabular}

The mass average $\mathrm{MW}=\sum \mathrm{Xi} \times \mathrm{Mi}$, where $\mathrm{Wi}$ is the mass fraction and $\mathrm{Mi}$ the average weight for interval i. Individual intervals were obtained from gel photographs, which were scanned; scans were divided into MW intervals calculated from the migration of standard DNA molecules. The number average $\mathrm{MW}: \mathrm{Mn}=\sum \mathrm{Xi} \times \mathrm{Mi}$, where $\mathrm{Xi}$ is number fraction for interval $\mathrm{i}$. For the number average distribution, the relative number of molecules under each interval was summed and the number in each interval of molecules was taken as a fraction of the total DNA. R is the ratio (MW/Mn), a change in the value of $r$ indicated a change in the shape of the distribution. Percentage of methylation $=1-($ Mn Msp I $) /($ Mn HpaII $) \times 100$

The reduction was in a dose-dependent manner. There was a highly significant reduction in MTX therapeutic, LD50 and ADR therapeutic as well as LD50 in comparison to control group $(p=0.0011,0.0033$, respectively). Significant difference was found especially in products of cleavage with enzyme MspI, where a decrease in DNA fragments of medium molecular weight (1 - $7 \mathrm{~kb}$ ) occurred between the therapeutic MTX dose and therapeutic ADR dose than control. MTX and ADR of acute and LD50 did not induce significant changes in molecular weight distribution of restriction fragments of DNA isolated from acute and LD50 treatment with MTX or ADR.

\section{DISCUSSION}

Epigenetic changes such as DNA methylation act to regulate gene expression in normal mammals. In the present study, the higher level of DNA methylation observed in control than treated female mice was probably connected with alterations in the gene expression of the hepatocytes. It was obviously recognized in the SDSPAGE for total soluble hepatic protein patterns. As it showed absence or presence of some protein bands after treatment with anti-cancer drugs comparing to untreated group. This finding is in agreement with the report of David [21] and this observation relies on the type of drug used and in a dose-dependent manner. Five bands had been shown with low molecular weight (16 - 6.1 $\mathrm{KDa})$ after treatment with acute or LD50 dose of ADR, and meanwhile with acute and LD50 dose of MTX. These bands were not observed either in the control or therapeutic ADR or therapeutic MTX. These bands can be considered as a potential marker associated with high dose of anticancer drugs. The changes in band intensity or density could be explained on the basis of cytogenetical abnormalities produced by these drugs. Donna et al., [22] concluded that the increase in band intensities or densities could be due to the gene duplication produced by induction of bridges, breaks, laggards, and micronuclei. The disappearance of some bands could be attributed to the loss of some genetic material. It seems possible that interaction of diet and contaminants or drugs by inducing changes in DNA methylation and aberrant gene expression. Specific methylation alterations are associated with changes in gene expression and this association is described by the simple hypothesis that methylation turns some genes off and others on. Our data and data from several studies indicated that DNA methylation changes are much complicated and its pattern is generally discontinuous. This can be observed by comparing Msp I partial digested DNA with comparable Hpa II digests. Since differential methylation clearly exists in DNA, it is likely that gene expression has evolved to utilize these differences (up and down of regulation different genes) [23]. This was strongly supported by our data and reflected by different protein banding pattern for the different treated groups of animal comparing to control. Inhibition of DNA methylation (hypomethylation) as a result of anti cancer drugs or post-radiation therapy had been reported by Igor, et al. [24]. Hypomethylation showed the loss of long interspersed nucleotide element-1 (LINE-1) CpG methylation in spleen.

Recent study of Basak, et al. [25] reported that the cytotoxic effect of MTX is associated with apoptosis enhancement, as it may be related to hyperhomocysteinemia and deoxyribonucleotide pool imbalances. Conclud- ing that there was an altered expression of MTHFR enhanced MTX - induced myelosuppression in mice, after evaluating that in the major hemolytic organ spleen. DNA methylation-related anticancer drugs had gained increasing attention over the past decades due to the aberrant DNA methylation to development of drug resistant tumors cells. Hence the acquired drug resistance represents a frequent obstacle which hampers efficient chemotherapy of cancers [26]. Recently, Boettcher et al. [27] characterized DNA methylation change which aris- 
es from treatment of tumor cells with the adriamycine. DNA methylation level from $\mathrm{CpG}$ islands linked to twenty eight genes whose expression levels had been shown to contribute with the resistance against DNA double strand break induced drugs. These data were supported in some way to our data in documenting DNA methylation by different doses of doxorubicin drug in non-tumor female mice [28] assessed the CpG methylation aberrations induced by pixantrone and doxorubicin. A characteristic that may determine the most cancer types to specific drug treatments and is a marker of drug sensitivity. Moreover, Winter-Vann, et al. [29] suggested that MTX has an additional mechanism of action besides it is a potent product inhibitor of cellular methyltransferases. It is also having an inhibitiory effect on Ras signaling that regulates cell growth and differentiation. Because carboxyl methylation of Ras is important for proper plasma membrane localization and function, they reported that after MTX treatment of DKOB8 cells, Ras methylation is decreased by almost $90 \%$ and subsequently inhibition of carboxyl methylation.

\section{CONCLUSIONS}

DNA methylation is influenced by anticancer drugs (MTX and ADR) and this influence was in a dosedependent manner; as they exhibited reduction in DNA methylation with varying degrees in liver genomic DNA. Some specific protein bands may be considered as a potential markers associated with high doses of anticancer drugs. Treatment with DNA methylation inhibitors may reactivate epigenetically silenced genes and has been shown to restore normal gene function. Further studies are recommended to characterize the protein fragments associated with anticancer drugs treatment.

\section{REFERENCES}

[1] Shkreta, L., Froehlich, U., Paquet, E.R., Toutant, J., Elela, S.A., Chabot, B. (2008) Anticancer drugs affect the alternative splicing of Bcl-x and other human apoptotic genes. Molecular Cancer Therapeutics, 7, 1398-1409. doi:10.1158/1535-7163.MCT-08-0192

[2] Laque-Ruperez, E., Ruiz-Gomez, M.J., de la Pena, L., Gil, L. and Martinez-Morillo, M. (2003) Methotrexate cytotoxicity on MCF-7 breast cancer cells is not altered by exposure to $25 \mathrm{~Hz}, 1.5 \mathrm{mT}$ magnetic field and iron (III) chloride hexahydrate. Bioelectrochemistry, 60, 81-86. doi:10.1016/S1567-5394(03)00054-9

[3] Senter, P.D., Vrudhula,V.M., Wallace, P.M., Somerville, J.A., Wang, I. and Lowe, D.A. (1995) Sulfated etoposide and nitrogen mustard prodrugs and their activation by streptomyces arylsulfatase. Drug Delivery, 2, 110-116. doi:10.3109/10717549509031358

[4] Cronstein, B.N., Naime, D. and Ostad, E. (1993) The anti-inflammatory mechanism of methotrexate: Increased adenosine release at inflamed sites diminishes leukocytes accumulation in an in vivo model of inflammation. Journal of Clinical Investigation, 92, 2675-2682.

doi:10.1172/JCI116884

[5] Rosenthal, G.J., Weigand, G.W. and Germolec, D.R. (1988) Suppression of B cell functions by methotrexate and trimethotrexate. Evidence for inhibition of purine biosynthesis as a major mechanism of action. The Journal of Immunology, 141, 410-416.

[6] Kosuke, Y., Kenichi, S., Motofumi, S., Atsuhiro, T., Sakiko, O., Hitomi, U., Shinichi, O., Jun, W., Ryo, N., Daisuke, O., Yasushi, S. and Hirofumi, M. (2005) Methotrexate Prevents Renal Injury in Experimental Diabetic Rats via Anti-Inflammatory Actions. Journal of the American Society of Nephrology, 16, 3326-3338. doi:10.1681/ASN.2004111011

[7] Mazzotta, P., Kwasnicka, A. and Kutas, G.J. (2001) Cancer Chemotherapy: The role of pharmacological agents in the management of haematological malignancies. University of Toronto Medical Journal, 79, 38-45.

[8] Hendrich, B. and Bird, A. (1998) Identification and charcterization of family of mammalian methyl-CpG binding proteins. Molecular and Cellular Biology, 18, 6538-6547.

[9] Antequera, F. (2003) Structure, function and evolution of $\mathrm{CpG}$ island promoters. Cellular and Molecular Life Sciences, 60, 1647-1658. doi:10.1007/s00018-003-3088-6

[10] Oakes, C.C., Smiraglia, D.J., Plass, C., Trasler, J.M., Robaire, B. (2003) Aging results in hypermethylation of ribosomal DNA in sperm and liver of female rats. Proceedings of the National Academy of Sciences of the Uniited States of Americia, 100, 1775-1789. doi: $10.1073 /$ pnas. 0437971100

[11] Freshney, R.I. (2005) Culture of Animal Cells, a Manual of Basic Technique. 5th Edition, John Wiley \& Sons, Hoboken. doi:10.1002/9780471747598

[12] Reitman, S. and Frankel, S. (1975) A colorimetric method for the determination of serum glutamic oxalacetic and glutamic pyruvic transaminases. American Journal of Clinical Pathology, 28, 56-63.

[13] Doumas, B., Watson, W. and Biggs, H. (1971) Albumin standards and the measurement of serum albumin with bromcresol green. Clinica Chimica Acta, 1, 87-96. doi:10.1016/0009-8981(71)90365-2

[14] Young, D.S. (2001) Effects of diseases on clinical lab. tests. 4th Edition, American Association for Clinical Chemistry, Inc., Washington DC.

[15] Bartels, H., Bohmer, M. and Heierli, C. (1972) Serum creatinine determination without protein precipitation. Clinica Chimica Acta, 37, 193-197. doi:10.1016/0009-8981(72)90432-9

[16] Tiez, N.W. (1976) Fundamentals of Clinical Chemistry. W.B. Saunders Co., Philadelphia.

[17] Portmann, B., Talbol, I.D. and Day, D.W. (1975) Histopathological changes in the liver following paracetamol overdose: Correlation with clinical and biochemical parameters. The Journal of Pathology, 117, 169-181. doi:10.1002/path.1711170307

[18] Laemmli, U.K. (1970) Cleavage of structure proteins during assembly of head bacteriophage T4. Nature, 227, 680-685. doi:10.1038/227680a0

[19] Bradford, M.M. (1976) A rapid and sensitive for the 
quantitation of microgram quantitites of protein utilizing the principle of protein-dye binding. Analytical Biochemistry, 72, 248-254. doi:10.1016/0003-2697(76)90527-3

[20] Sambrook, J., Fritch, E. and Maniatis, T. (1989) Molecular cloning: A laboratory manual (DNA methylation). Cold Spring Harbor Lab. Press, 5, 1-35.

[21] David, G. (2001) Chromosomal instability in cancercauses and consequenes of genetics and cytogeneticsin. Oncology and Haematology, 1, 13.

[22] Donna, G., Albertson, C., Frank, C., Mcormick, F. and Gray, G.W. (2003) Chromosomeaberration in solid tumors. Nature Genetics, 34, 369-376.

[23] Kozurkova, M., Letavayova, L. and Misrurova, E. (2007) Influence of gamma irradiation on DNA methylation in liver of male rats and their offspring. Acta Veterinaria Brasilica, 76, 215-222. doi:10.2754/avb200776020215

[24] Igor, K., Bokyo, A., Juarez, R.R., Mcdonald, R.J., Tryndyak, V.P., Kovalchuk, I., Pogribny, I.P. and Kovalchuk, O. (2007) Role of epigenetic effectors in maintenance of the long-term persistent bystander effect in spleen in vivo. Carcinogenesis, 28, 1831-1838. doi:10.1093/carcin/bgm053

[25] Basak, C., Andeerea, K.L., Qing, W. and Rima, R. (2009)
Methotrexate-induced apoptosis is enhanced by alterd expression of methylenetetrahydrofolate reductase. AntiCancer Drugs, 20, 787-793. doi:10.1097/CAD.0b013e32832f4aa8

[26] Viller-Garea, A. (2003) Procaine is a DNA-demethylating agent with growth-inhibitory effects in human cancer cell. Cancer Resarch, 63, 4948-4989.

[27] Boettcher, M., Kischkel, F. and Hoheisel, J.D. (2010) High-definition DNA methylation profiles from breast and ovarian carcinoma cell lines with differing doxorubicin resistance. PLOS ONE, 5, Article ID e1 1002.

[28] Evison, B.J., Bilard, R.A., Chiu, F.C.K., Pezzoni, G., Phillips, D.R. and Cutts, S.M. (2009) CpG methylation potentiates pixantrone and doxorubicin-induced DNA damage and is a marker of drug sensitivity. Life Sciences, 37, 6355-6370.

[29] Winter-Vann, A.M., Kamen, B.A., Bergo, M.O., Young, S.G., Melenyk, S., James, S.J. and Casey, P.J. (2003) Targeting Ras signaling through inhibition of carboxyl methylation:anunexpected properity of methotrexate. Proceedings of the National Academy of Sciences of the Uniited States of Americia, 100, 6529-6234. doi:10.1073/pnas. 1135239100 